\title{
A Study on the Characteristics of $\mathrm{Cu}-\mathrm{Mn}-\mathrm{Dy}$ Alloy Resistive Thin Films
}

\author{
Ho-Yun Lee ${ }^{1}$, Chi-Wei He ${ }^{2}$, Ying-Chieh Lee ${ }^{2, *}$ and Da-Chuan Wu ${ }^{3}$ \\ 1 Department of Material Science and Engineering, École polytechnique fédérale de Lausanne (EPFL), \\ 1010 Lausanne, Switzerland; Lillian9620227@gmail.com \\ 2 Department of Materials Engineering, National Pingtung University of Science \&Technology, \\ Pingtung 91201, Taiwan; d7346203@gmail.com \\ 3 ZEUS International Management Consultant Company, Kaohsiung 80147, Taiwan; \\ DCWU0614@PCHOME.COM.TW \\ * Correspondence: YCLee@mail.npust.edu.tw; Tel.: +886-8-770-3202 (ext. 7556)
}

Received: 23 January 2019; Accepted: 11 February 2019; Published: 13 February 2019

\begin{abstract}
Cu}-\mathrm{Mn}-\mathrm{Dy}$ resistive thin films were prepared on glass and $\mathrm{Al}_{2} \mathrm{O}_{3}$ substrates, which was achieved by co-sputtering the $\mathrm{Cu}-\mathrm{Mn}$ alloy and dysprosium targets. The effects of the addition of dysprosium on the electrical properties and microstructures of annealed $\mathrm{Cu}-\mathrm{Mn}$ alloy films were investigated. The composition, microstructural and phase evolution of $\mathrm{Cu}-\mathrm{Mn}-\mathrm{Dy}$ films were characterized using field emission scanning electron microscopy, transmission electron microscopy and X-ray diffraction. All Cu-Mn-Dy films showed an amorphous structure when the annealing temperature was set at $300{ }^{\circ} \mathrm{C}$. After the annealing temperature was increased to $350{ }^{\circ} \mathrm{C}$, the $\mathrm{MnO}$ and $\mathrm{Cu}$ phases had a significant presence in the $\mathrm{Cu}-\mathrm{Mn}$ films. However, no $\mathrm{MnO}$ phases were observed in $\mathrm{Cu}-\mathrm{Mn}-\mathrm{Dy}$ films at $350{ }^{\circ} \mathrm{C}$. Even $\mathrm{Cu}-\mathrm{Mn}-\mathrm{Dy}$ films annealed at $450{ }^{\circ} \mathrm{C}$ showed no $\mathrm{MnO}$ phases. This is because Dy addition can suppress $\mathrm{MnO}$ formation. $\mathrm{Cu}-\mathrm{Mn}$ alloy films with $40 \%$ dysprosium addition that were annealed at $300{ }^{\circ} \mathrm{C}$ exhibited a higher resistivity of $\sim 2100 \mu \Omega \cdot \mathrm{cm}$ with a temperature coefficient of resistance of $-85 \mathrm{ppm} /{ }^{\circ} \mathrm{C}$.
\end{abstract}

Keywords: CuMn alloy; dysprosium; thin film resistors; resistivity; TCR

\section{Introduction}

One of the fundamental passive components is the thin film resistor, which is applied primarily in electronic circuits. Thin film resistors have exceptional properties, such as a low temperature coefficient of resistance, high precision, high stability and low noise, and are commonly used in precision electronic equipment [1-3].

Copper-manganese alloy films with high thermal stability and low resistance are usually used in mobile electronic devices. Copper allows for low electrical resistivity and manganese produces thermal stability in this $\mathrm{Cu}-\mathrm{Mn}$ alloy system [4]. Based on the equilibrium phase diagram, there are no intermetallic phases in the $\mathrm{Cu}-\mathrm{Mn}$ system. Copper can serve as a substitute species for Mn in the FCC (Face Centered Cubic) lattice [5]. A characteristic feature of $\mathrm{Mn}$ in $\mathrm{Cu}$ is its larger activity coefficient compared to other elements that have limited solubility, such as $\mathrm{Al}$ and $\mathrm{Mg}$ [6]. This feature makes the $\mathrm{Cu}-\mathrm{Mn}$ solid solution less stable than other $\mathrm{Cu}$ alloys when a stable reaction, such as Mn oxidation, can take place. Thus, Mn does not tend to precipitate or segregate within the $\mathrm{Cu}$ film but can easily diffuse out to the surface and interface under oxidative conditions [7].

Misjak et al. reported on the specific resistivity of $\mathrm{Cu}-\mathrm{Mn}$ films, which they measured over the whole composition range [8]. The resistivities of pure $\mathrm{Cu}$ and $\mathrm{Mn}$ films were $1.7 \mu \Omega \cdot \mathrm{cm}$ and $174 \mu \Omega \cdot \mathrm{cm}$, respectively. The curve increased monotonically when the Mn content was 0-80 at.\%, with a maximum 
of $205 \mu \Omega \cdot \mathrm{cm}$ at 80 at.\% Mn that corresponds to a temperature coefficient of resistance (TCR) of $-308 \mathrm{ppm} /{ }^{\circ} \mathrm{C}$ [8]. Focusing on the electrical properties of $\mathrm{Cu}_{0.5}-\mathrm{Mn}_{0.5}$ alloy films, the resistivity was about $137 \mu \Omega \cdot \mathrm{cm}$ with a TCR of $-377 \mathrm{ppm} /{ }^{\circ} \mathrm{C}$. However, the TCR value was too high, which would have to be improved for applications in mobile electronic devices.

In order to minimize the resistance change in $\mathrm{Cu}-\mathrm{Mn}$ alloy films, foreign elements are added to improve the TCR. The addition of dysprosium was attempted to improve the electrical properties of $\mathrm{Cu}-\mathrm{Mn}$ resistive films since rare earth doping has been used as an effective way to regulate the electrical properties of oxides [9-11]. Dysprosium has a larger resistivity $(92.6 \mu \Omega \cdot \mathrm{cm})$ and a higher melting point $\left(1407^{\circ} \mathrm{C}\right)$. Dy may be beneficial for the enhancement of resistivity and the minimization of TCR in thin films. The effects of Dy content and annealing temperature on the phases, microstructural and electrical properties of $\mathrm{Cu}-\mathrm{Mn}$ thin films are investigated in this study.

\section{Experimental Procedure}

\section{1. $\mathrm{Cu}-\mathrm{Mn}-\mathrm{Dy}$ Thin Film}

$\mathrm{Cu}-\mathrm{Mn}-\mathrm{Dy}$ thin films with a thickness of $80 \mathrm{~nm}$ were prepared on substrates using a direct current (DC) and radio frequency (RF) magnetron co-sputtering system. $\mathrm{A} \mathrm{Cu}_{0.5}-\mathrm{Mn}_{0.5}$ alloy and dysprosium with a diameter of $76.2 \mathrm{~mm}$ were used as targets (purities of $99.95 \%$ and $99.9 \%$, respectively). The $\mathrm{Cu}_{0.5}-\mathrm{Mn}_{0.5}$ alloy target was set at the DC position. The dysprosium target was set at the RF position. To obtain different dysprosium contents in the $\mathrm{Cu}_{0.5}-\mathrm{Mn}_{0.5}$ alloy film, the DC power was fixed at $50 \mathrm{~W}$, and the RF power was changed from $40 \mathrm{~W}$ to $70 \mathrm{~W}$. A background pressure of $4 \times 10^{-7}$ torr was maintained using a cryo-pump in the sputtering chamber. The sputtering of argon gas with a purity of $99.999 \%$ at a flow rate of $60 \mathrm{sccm}$ was executed using mass flow controllers, and the working pressure was maintained at $3 \times 10^{-3}$ torr. In order to measure TCR, $\mathrm{Cu}-\mathrm{Mn}$ films were deposited onto polished $\mathrm{Al}_{2} \mathrm{O}_{3}$ substrates. These alumina substrates with cell sizes of $1.6 \times 0.8 \mathrm{~mm}^{2}$ were used in this study. Glass with dimensions of $20 \times 10 \mathrm{~mm}^{2}$ and silicon wafers with dimensions of $10 \times 10 \mathrm{~mm}^{2}$ were used for the sheet resistance measurements and thin film thickness, respectively.

\subsection{Analysis}

Alloy films deposited onto the glass substrate at room temperature were subjected to microstructure (transmission electron microscopy) and phase evolution (X-ray diffraction) analysis. Alloy films deposited onto $\mathrm{Al}_{2} \mathrm{O}_{3}$ substrates with Ag electrodes were used to measure the resistance and TCR. The as-deposited films were annealed at $250-450{ }^{\circ} \mathrm{C}$ for $2 \mathrm{~h}$ at a heating rate of $5{ }^{\circ} \mathrm{C} / \mathrm{min}$ in a $\mathrm{N}_{2}$ atmosphere. $\mathrm{N}_{2}$ gas with a purity of $99.99 \%$ was used in this study.

The sheet resistance $R_{\mathrm{s}}$ is commonly used to characterize materials made by thin film deposition, which was measured using the four-point probe technique. The thickness of $\mathrm{Cu}-\mathrm{Mn}$-Dy films after co-sputtering was measured using field-emission scanning electron microscopy (FE-SEM, Hitachi S-4700 Japan, Tokyo, Japan) on a cross-section of the film. The resistivity measurement of specimens using the four-probe method was consistent with the resistivity obtained by the $R_{\text {sheet }}$ and film thickness " $t$ ". The resistance of the specimens was measured using a digital multimeter (HP 34401A, Santa Clara, CA, USA) at different temperatures. The specimens were soaked for 6 minutes at the set temperatures before measuring the electrical properties while the TCR values of the specimens were calculated using Equation (1) with the resistance at $25^{\circ} \mathrm{C}$ and the resistance at $125^{\circ} \mathrm{C}$ [1]:

$$
T C R=[(\Delta R / \Delta T) \times 1 / R] \times 10^{6} \mathrm{ppm} / \mathrm{K}
$$

X-ray diffraction (XRD, Bruker D8A Germany, Mannheim, Germany) and an electron probe micro-analyzer (EPMA, JEOL JXA-8900R Electron Probe X-ray Microanalyzer, Tokyo, Japan) were used to determine the crystalline phases and the compositions of the thin films, respectively. Microstructural, selected area diffraction (SAD) patterns and EDS (energy dispersive spectroscopy) analysis of the specimens were executed using a field-emission transmission electron microscope (FE-TEM, FEIE.O. 
Tecnai F20, Eindhoven, The Netherlands) equipped with an energy dispersive spectrometer at an accelerating voltage of $200 \mathrm{kV}$.

\section{Results and Discussion}

$\mathrm{Cu}-\mathrm{Mn}-\mathrm{Dy}$ alloy films were deposited onto the substrates using a DC and RF magnetron co-sputtering system. The compositions of the as-deposited film were examined using the electron probe micro-analyzer (EPMA). The relative concentrations of copper, manganese and dysprosium were analyzed at three points in the deposited films. The measured data for copper, manganese and dysprosium are listed in Table 1. The dysprosium content was increased with an increase in the RF sputtering power in the Cu-Mn films. For example, Dy increased from 20.5 at. $\%$ at $40 \mathrm{~W}$ to 40.0 at. $\%$ at $70 \mathrm{~W}$.

Table 1. Compositions of $\mathrm{Cu}-\mathrm{Mn}-\mathrm{Dy}$ thin films prepared at a direct current (DC) $50 \mathrm{~W}$ with different radio frequency $(\mathrm{RF})$ powers sputtered on cooper sheet.

\begin{tabular}{ccccc}
\hline Power (W) & DC/RF & $\mathbf{5 0 / 4 0}$ & $\mathbf{5 0 / 5 5}$ & $\mathbf{5 0 / 7 0}$ \\
\hline \multirow{3}{*}{ Element (at.\%) } & $\mathrm{Cu}$ & 52.3 & 45.5 & 37 \\
\cline { 2 - 5 } & $\mathrm{Mn}$ & 27.2 & 24.5 & 23 \\
\cline { 2 - 5 } & $\mathrm{Dy}$ & 20.5 & 30 & 40 \\
\hline
\end{tabular}

Figure 1 shows $\mathrm{X}$-ray diffraction patterns of the as-deposited and annealed $\mathrm{Cu}-\mathrm{Mn}$ films with different added amounts of dysprosium, which were deposited on glass substrates. Annealing was performed in a $\mathrm{N}_{2}$ atmosphere at a temperature up to $450{ }^{\circ} \mathrm{C}$. All of the $\mathrm{Cu}-\mathrm{Mn}-\mathrm{Dy}$ films annealed at $\leq 350{ }^{\circ} \mathrm{C}$ displayed an amorphous structure, except for alloy films without Dy addition (Figure 1a,b). When the annealing temperature was set at $450{ }^{\circ} \mathrm{C}$, a Cu crystallization phase with a (111) peak was clearly observed in the $\mathrm{Cu}-\mathrm{Mn}-\mathrm{Dy}$ films. An additional (200) diffraction peak of the $\mathrm{Cu}_{2} \mathrm{O}$ phase appeared in the $\mathrm{Cu}-\mathrm{Mn}-\mathrm{Dy}$ films after annealing at $450{ }^{\circ} \mathrm{C}$ as shown in Figure 1c. This demonstrates that none of the elements were crystallized or oxidized in $\mathrm{Cu}-\mathrm{Mn}$ films with Dy addition after annealing at $300{ }^{\circ} \mathrm{C}$ in a $\mathrm{N}_{2}$ atmosphere. However, two crystallization phases ( $\mathrm{Cu}$ and $\mathrm{MnO}$ ) appeared in $\mathrm{Cu}-\mathrm{Mn}$ alloy films without Dy addition as shown in Figure 1. The crystallization strength of the MnO peaks also increased with increased annealing temperatures. This is believed to be due to the oxidation of the $\mathrm{Cu}-\mathrm{Mn}$ alloy film during annealing. Iijima et al. reported that $\mathrm{Mn}$ does not tend to precipitate or segregate within the $\mathrm{Cu}$ film but can easily diffuse out to the surface and interface under oxidative conditions [6,12]. In contrast, $\mathrm{Mn}$ at the interface can be selectively oxidized by reacting with oxygen under proper conditions. In our study, the samples were annealed in a $\mathrm{N}_{2}$ atmosphere. Why did the $\mathrm{MnO}$ cause oxidation in the alloy films? Further studies of the microstructure of alloy film with transmission electron microscopy will be performed and discussed later.

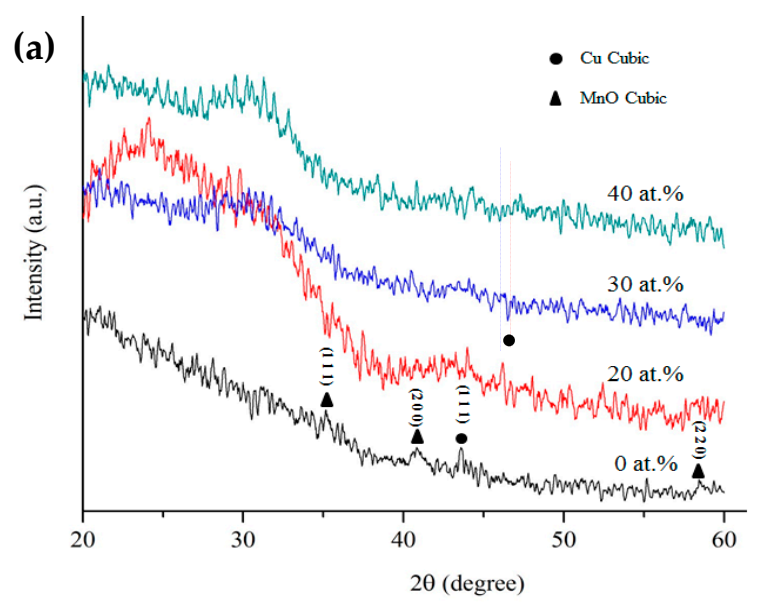

Figure 1. Cont. 

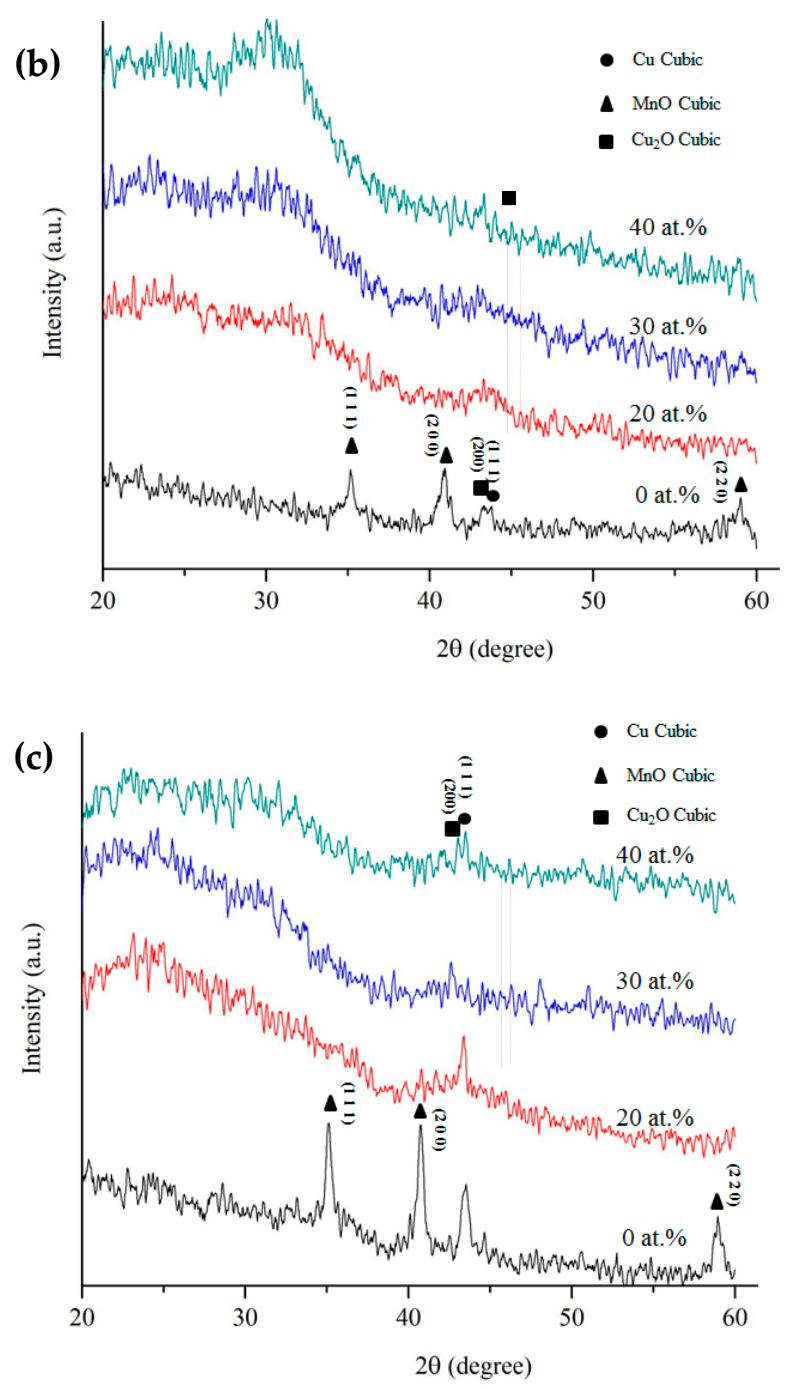

Figure 1. X-ray diffraction patterns of $\mathrm{Cu}-\mathrm{Mn}-\mathrm{Dy}$ thin films with various amounts of dysprosium addition annealed at (a) $300{ }^{\circ} \mathrm{C}$; (b) $350{ }^{\circ} \mathrm{C}$; and (c) $450{ }^{\circ} \mathrm{C}$.

Figure 2 shows a cross-section TEM micrograph, SAD and Energy Dispersive X-ray Analysis EDX analysis of $\mathrm{Cu}-\mathrm{Mn}$ films without Dy addition that was annealed at $300{ }^{\circ} \mathrm{C}$. The film thickness is about $60 \mathrm{~nm}$ as shown in Figure 2a. This shows that there are different crystalline structures between the upper and lower layers in $\mathrm{Cu}-\mathrm{Mn}$ alloy films. In the lower layer, $\mathrm{MnO}$ crystallites are present as demonstrated using SAD analysis (Figure 2c). Regarding $\mathrm{MnO}$ formation, it is believed that oxygen from the $\mathrm{Al}_{2} \mathrm{O}_{3}$ substrate reacted with Mn during annealing because the $\mathrm{MnO}$ phase exists in the lower layer of the alloy film. In the upper layer, the $\mathrm{Cu}_{2} \mathrm{O}$ phase was found according to SAD analysis as shown in Figure 2d. This result indicates that the $\mathrm{Cu}-\mathrm{Mn}$ alloy film surface can be oxidized to cause the formation of the $\mathrm{Cu}_{2} \mathrm{O}$ phase during annealing in a $\mathrm{N}_{2}$ atmosphere. Under $\mathrm{N}_{2}$ annealing, the surface of $\mathrm{Cu}-\mathrm{Mn}$ alloy films was oxidized due to the presence of oxygen and/or moisture inside the chamber/furnace $[13,14]$. Copper only forms two thermodynamically stable oxides, namely $\mathrm{CuO}$ and $\mathrm{Cu}_{2} \mathrm{O}$. From the Gibbs free energy point of view, the $\mathrm{Cu}_{2} \mathrm{O}$ phase likely formed first because the $\mathrm{Cu}_{2} \mathrm{O}$ phase $\left(\Delta G_{0}=-122 \mathrm{KJ} / \mathrm{mol}\right)$ formation has a lower Gibbs free energy than the $\mathrm{CuO}$ phase $\left(\Delta G_{0}=-99 \mathrm{KJ} / \mathrm{mol}\right)[15,16]$. Moreover, Luo et al. reported that only $\mathrm{Cu}_{2} \mathrm{O}$ is expected to form at very low oxygen partial pressures [17]. A similar oxidation phenomenon occurred for $\mathrm{Cu}-\mathrm{Mn}$ alloy films annealed in pure $\mathrm{Ar}$ at $350^{\circ} \mathrm{C}$ for $1800 \mathrm{~s}$. On the other hand, the $\mathrm{Cu}^{2+}$ ion has a greater charge density than the $\mathrm{Cu}^{+}$ion; thus, it forms much stronger bonds that release more energy. $\mathrm{Cu}^{2+}$ is more stable 
than $\mathrm{Cu}^{+}$in an aqueous medium. Wang et al. reported that $\mathrm{Cu}^{2+}$ cations react with metallic $\mathrm{Cu}$ to form $\mathrm{Cu}^{+}$through a disproportionation reaction, with these unstable $\mathrm{Cu}^{+}$cations subsequently rapidly reacting with $\mathrm{O}-\mathrm{O}_{(\text {adsorb })}$ to form $\mathrm{Cu}_{2} \mathrm{O}[18]$.

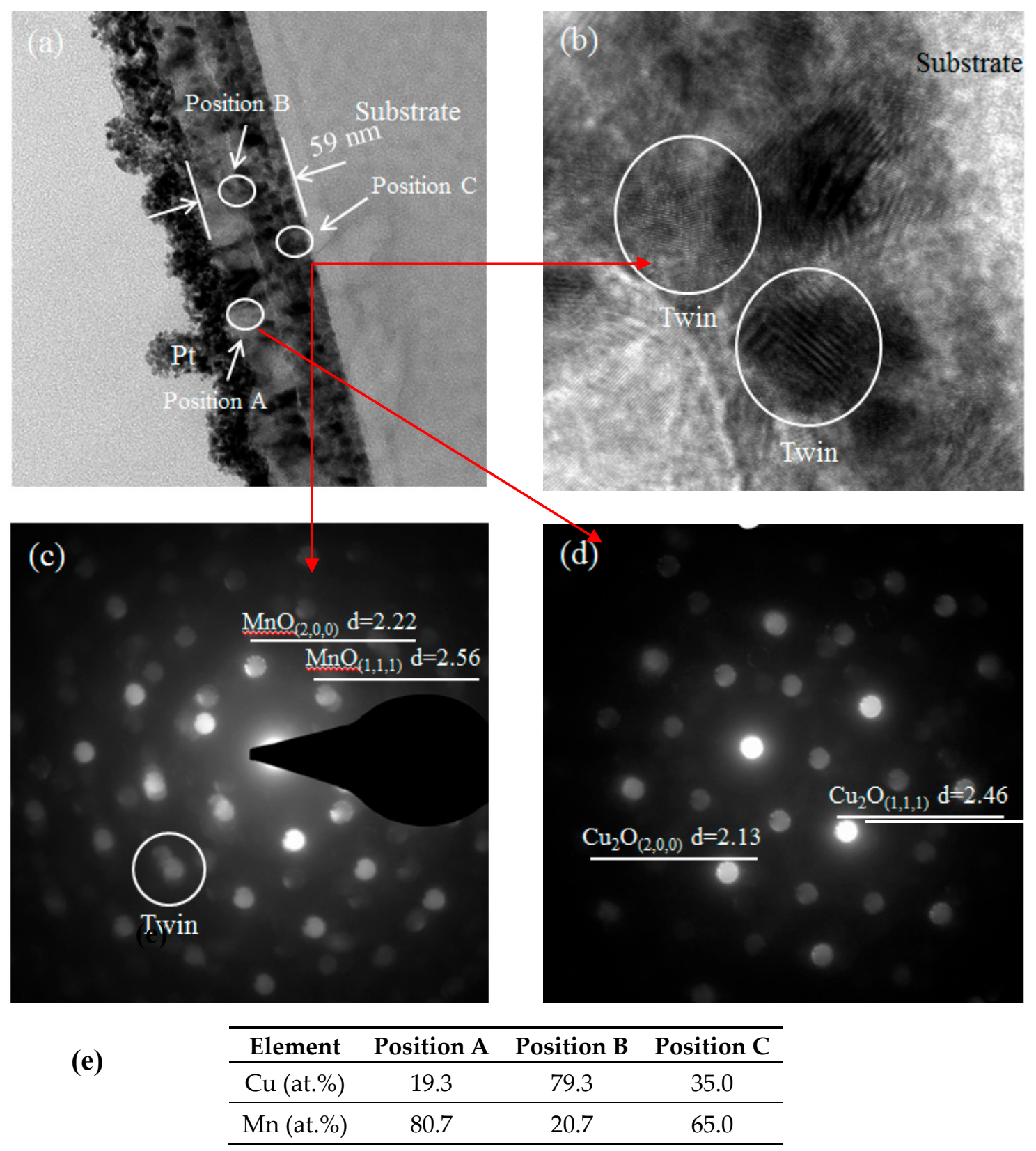

Figure 2. TEM micrographs of $\mathrm{Cu}-\mathrm{Mn}$ films annealed at $300{ }^{\circ} \mathrm{C}$ : (a) bright field of cross section; (b) HRTEM micrographs; (c) selected-area electron diffraction at position C; (d) selected-area electron diffraction at position A; (e) Energy Dispersive X-ray Analysis EDX analysis.

The sample surface shows the formation of a discontinuous oxide layer [6]. The EDX analysis conducted using different positions in the $\mathrm{Cu}-\mathrm{Mn}$ film is listed in Figure 2e. The $\mathrm{Cu} / \mathrm{Mn}$ ratios differed greatly between the bottom, middle and surface areas of the film as they were $0.24,3.4$ and 0.54 , respectively. This result indicates that the copper atoms are concentrated in the middle of the film while the manganese atoms are distributed on the surface and bottom. Haruhiko Asanuma et al. [12] reported that Mn migrates toward the interface and reacts with a surface oxide layer until, finally, a Mn complex oxide layer is formed during subsequent annealing [19,20]. 
Figure 3 displays a cross-section TEM micrograph, EDX and SAD analysis of $\mathrm{Cu}-\mathrm{Mn}$ alloy films with 40 at.\% Dy addition that was annealed at $300{ }^{\circ} \mathrm{C}$. There is an oxidation layer with a thickness of $3 \mathrm{~nm}$ on the surface as shown in Figure 3a. The oxidation layer can also be called a passivation layer. However, an amorphous structure was observed in the alloy films, which is evident from the halo SAD patterns and high-resolution transmission electron microscopy as shown in Figure 3b,c. This result is consistent with the XRD analysis (Figure 1). It was noted that the $\mathrm{Cu}-\mathrm{Mn}-\mathrm{Dy}$ thin films had an amorphous structure at $300{ }^{\circ} \mathrm{C}$. Unlike the $\mathrm{Cu}-\mathrm{Mn}$ alloy films, there were some crystalline phases observed after annealing at $300{ }^{\circ} \mathrm{C}$ This may be attributed to the multiple element alloy effect, which could be explicated by the kinetics theory because of slow atomic diffusion [21,22]. This means that dysprosium addition in $\mathrm{Cu}-\mathrm{Mn}$ films leads to the formation of an amorphous structure and oxidation resistance after annealing at $300{ }^{\circ} \mathrm{C}$. The EDX analyzed positions in the $\mathrm{Cu}-\mathrm{Mn}-\mathrm{Dy}$ film are listed in Figure 3d. This table shows that the element distribution for $\mathrm{Cu}, \mathrm{Mn}$ and Dy was more uniform between the top and bottom parts of the film.
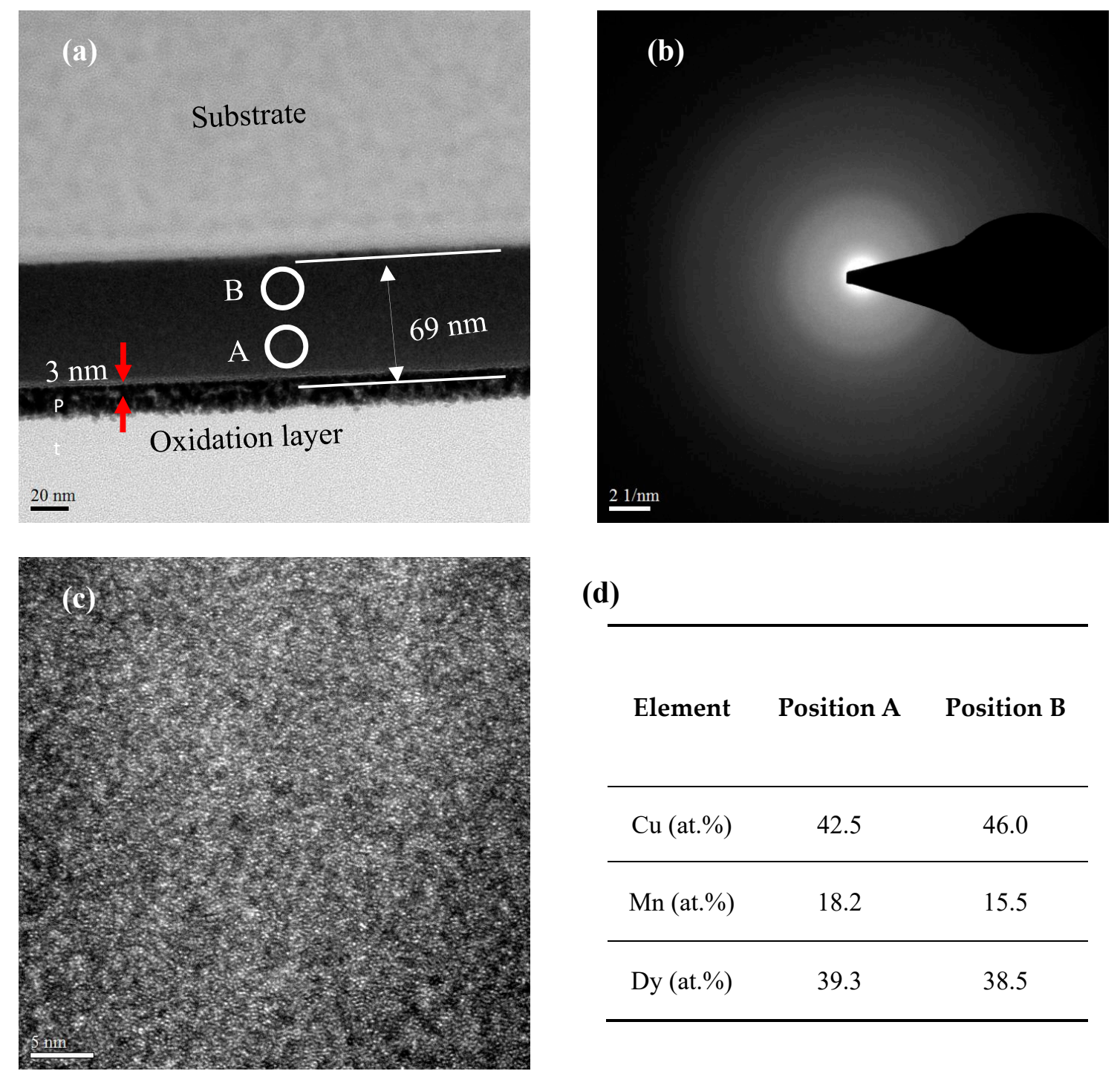

(d)

\begin{tabular}{ccc} 
Element & Position A & Position B \\
\hline $\mathrm{Cu}$ (at.\%) & 42.5 & 46.0 \\
\hline $\mathrm{Mn}$ (at.\%) & 18.2 & 15.5 \\
\hline Dy (at.\%) & 39.3 & 38.5 \\
\hline
\end{tabular}

Figure 3. TEM micrographs of $\mathrm{Cu}-\mathrm{Mn}$ films with 40 at.\% Dy addition annealed at $300{ }^{\circ} \mathrm{C}$ : (a) bright field of cross section; (b) selected-area electron diffraction; (c) HRTEM micrographs; (d) EDX analysis.

Figure 4 shows a cross-section TEM micrograph, EDX and SAD analysis of $\mathrm{Cu}-\mathrm{Mn}$ films with 40 at. $\%$ Dy addition that was annealed at $350{ }^{\circ} \mathrm{C}$. When the annealing temperature was increased to 
$350{ }^{\circ} \mathrm{C}$, there was an oxidation layer with a thickness of $5 \mathrm{~nm}$ on the surface as shown in Figure $4 \mathrm{a}$. A 5-nm crystalline layer on the film bottom was observed using high-resolution transmission electron microscopy analysis as shown in Figure $4 \mathrm{~b}$. According to the SAD pattern analysis, this crystalline layer belongs to the $\mathrm{Cu}$ crystallization structure, as shown in Figure 4c. It is known that amorphous thin films are in a metastable state. The heat treatments can initiate ordering processes, such as structural relaxation and crystallization [23]. To further observe and determine the size of precipitated particles, HRTEM was used. Some microcrystallites appeared on the surface films, as shown in Figure $4 \mathrm{~d}$. The precipitated particles were distributed on the amorphous matrix and had a size smaller than $5 \mathrm{~nm}$. The nanobeam electron diffraction pattern is shown in Figure 4e, which demonstrates that these microcrystallites belong to the $\mathrm{Cu}_{2} \mathrm{O}$ phase. The EDX was analyzed using different positions in the $\mathrm{Cu}-\mathrm{Mn}-\mathrm{Dy}$ film, as shown in Figure 4f. Unlike $\mathrm{Cu}-\mathrm{Mn}$ alloy films (Mn atoms are distributed on the surface and bottom), we found that $\mathrm{Mn}$ atoms had a more uniform distribution in the $\mathrm{Cu}-\mathrm{Mn}-\mathrm{Dy}$ annealed films compared to $\mathrm{Cu}-\mathrm{Mn}$ annealed films.
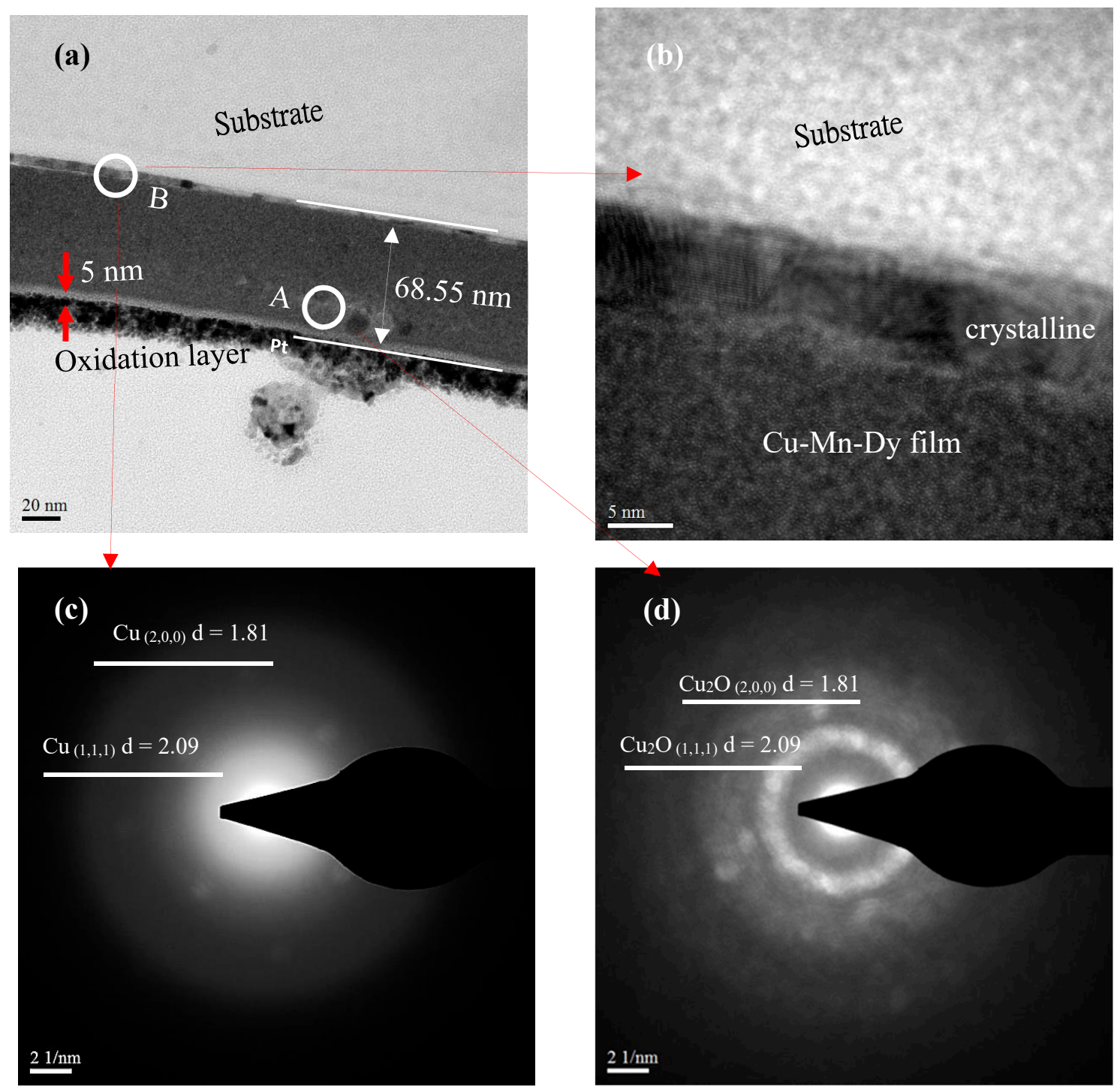

Figure 4. Cont. 


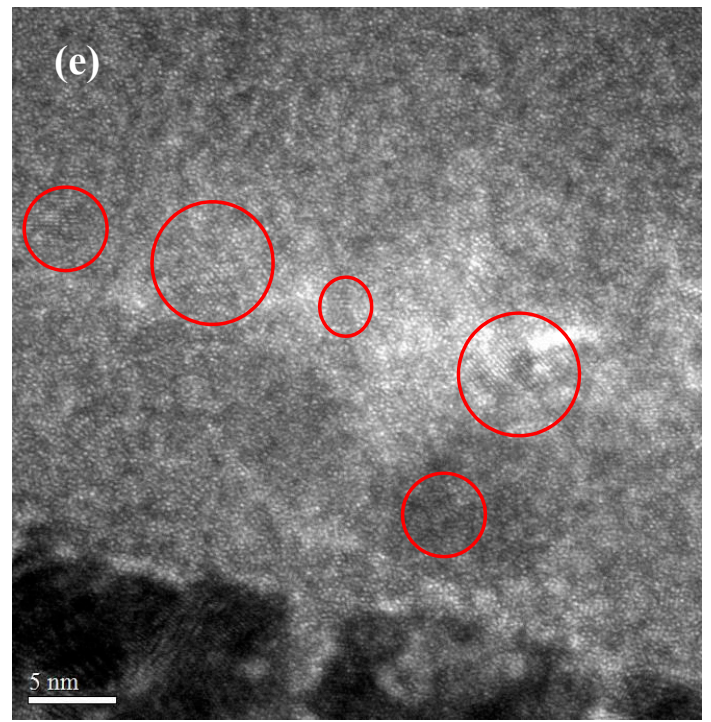

(f)

Element Position A Position B

\begin{tabular}{lcc}
\hline $\mathrm{Cu}$ (at.\%) & 40.0 & 69.9 \\
\hline Mn (at.\%) & 17.6 & 13.9 \\
\hline Dy (at.\%) & 42.4 & 16.2 \\
\hline
\end{tabular}

Figure 4. TEM micrographs of $\mathrm{Cu}-\mathrm{Mn}$ films with 40 at.\% Dy addition annealed at $350{ }^{\circ} \mathrm{C}$ : (a) bright field of cross-section, (b) HRTEM micrographs at position B, (c) selected-area electron diffraction of position B, (d) selected-area electron diffraction of position A, (e) HRTEM micrographs at position A, (f) EDX analysis.

The X-ray photoelectron spectroscopy (XPS) analysis included survey scans to understand the elemental composition at different depths. The compositions of the $\mathrm{Cu}-\mathrm{Mn}-\mathrm{Dy}$ film with 40 at.\% Dy addition that was annealed at $300{ }^{\circ} \mathrm{C}$ were analyzed using electron spectroscopy for chemical analysis (ESCA) as listed in Table 2. It was noted that the oxygen concentration significantly differed between the film surface and interior area (at a depth of $28 \mathrm{~nm}$ ). The oxygen concentrations for the film surface and interior area were 68.9 at.\% and 1.6 at.\%, respectively. This result indicates that the surface of $\mathrm{Cu}-\mathrm{Mn}-\mathrm{Dy}$ film was oxidized. The same result was obtained by TEM analysis as shown in Figure 3a.

Table 2. Compositions of $\mathrm{Cu}-\mathrm{Mn}$ films with 40 at.\% Dy addition annealed at $300{ }^{\circ} \mathrm{C}$ using electron spectroscopy for chemical analysis (ESCA).

\begin{tabular}{ccc}
\hline Element & Surface & Internal \\
\hline $\mathrm{Cu}$ (at.\%) & 8.8 & 47.6 \\
\hline $\mathrm{Mn}$ (at.\%) & 7.4 & 9.3 \\
\hline $\mathrm{Dy}$ (at.\%) & 14.9 & 41.5 \\
\hline $\mathrm{O}$ (at.\%) & 68.9 & 1.6 \\
\hline
\end{tabular}

Figure 5 shows the effects of dysprosium addition on the electrical properties of annealed $\mathrm{Cu}-\mathrm{Mn}$ films. The resistivity of $\mathrm{Cu}-\mathrm{Mn}$ films increased with an increase in dysprosium. Dy addition enhanced the resistivity of $\mathrm{Cu}-\mathrm{Mn}$ films. There are two reasons to explain this phenomenon: (1) dysprosium has a higher resistivity $(92.6 \mu \Omega \cdot \mathrm{cm})$ that contributes to the alloy film resistivity and (2) an amorphous structure in the alloy film can be obtained by Dy addition. However, it was noted that the resistivity of $\mathrm{Cu}-\mathrm{Mn}$-Dy film increased significantly after annealing at $350^{\circ} \mathrm{C}$. This is due to the increase in the oxidation of the alloy film after annealing at $350{ }^{\circ} \mathrm{C}$ compared to $300^{\circ} \mathrm{C}$ since $\mathrm{Cu}_{2} \mathrm{O}$ microcrystallites exist at $350{ }^{\circ} \mathrm{C}$ (Figure 4e). The resistivities of $\mathrm{Cu}-\mathrm{Mn}$ films with 40 at.\% Dy addition were $\sim 2100$ and $\sim 1200 \mu \Omega \cdot \mathrm{cm}$ after annealing at $250{ }^{\circ} \mathrm{C}$ and $300{ }^{\circ} \mathrm{C}$, respectively. Generally speaking, the resistivity of alloy film increases with an increase in the annealing temperature because the grain boundaries, crystal defects and oxides generation are increased after annealing [3]. Nevertheless, many scattering behaviors are believed to affect the resistivity of $\mathrm{Cu}-\mathrm{Mn}-\mathrm{Dy}$ films, which includes surface scattering, 
grain boundaries scattering, rough surfaces scattering, impurities scattering and oxides generation [24]. However, we hypothesize that the generation of oxides plays an important role in determining the electrical properties of $\mathrm{Cu}-\mathrm{Mn}-\mathrm{Dy}$ films.

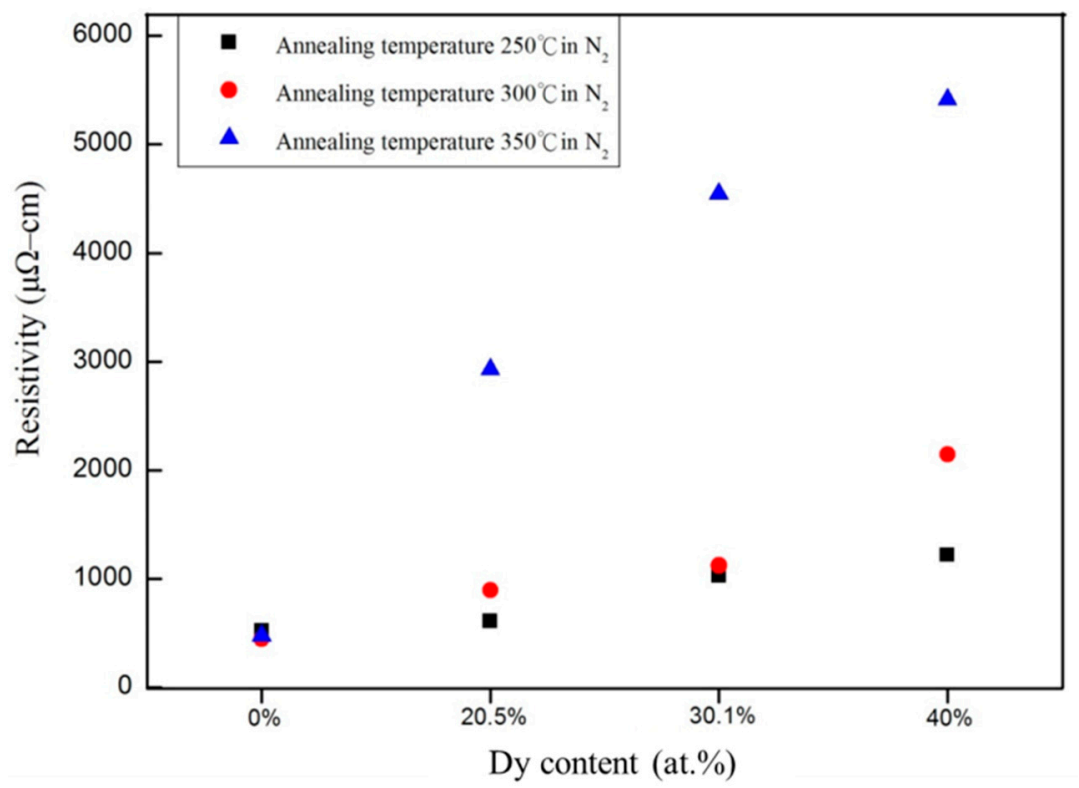

Figure 5. Room temperature resistivity of $\mathrm{Cu}-\mathrm{Mn}$ films with various Dy contents annealed at different temperatures.

Figure 6 shows the effects of dysprosium addition and annealing temperature on the temperature coefficient of resistivity (TCR) of $\mathrm{Cu}-\mathrm{Mn}$ films in a nitrogen atmosphere at ambient temperatures for $2 \mathrm{~h}$. The annealing treatment is an important factor in determining the resistor stability of the thin film. When the annealing temperature is $\leq 300^{\circ} \mathrm{C}$, the TCR changes significantly from approaching zero to having a positive value with increasing Dy content, except for specimens with 40 at. $\%$ Dy addition. As the annealing temperature was increased to $350{ }^{\circ} \mathrm{C}$, the TCR values rapidly increased, except for specimens with 40 at.\% Dy addition, which may be caused by the presence of $\mathrm{Cu}$ microcrystallites. As the alloy films crystallized, the TCR became positive because the majority of all metals have a positive TCR $[25,26]$. However, the TCR values suddenly changed from positive to negative when the Dy addition was increased to 40 at.\%. This may be due to the increased $\mathrm{Cu}_{2} \mathrm{O}$ formation on the surface (producing an oxidation layer), as shown in Figures 1 and 4. This result implies that the TCR value is strongly dependent on Dy content in the $\mathrm{Cu}-\mathrm{Mn}$ films. The $\mathrm{Cu}-\mathrm{Mn}$ films with 40 at.\% Dy addition displayed a resistivity of $\sim 2100 \mu \Omega \cdot \mathrm{cm}$ with the smallest TCR $\left(-85 \mathrm{ppm} /{ }^{\circ} \mathrm{C}\right)$ after annealing at $300{ }^{\circ} \mathrm{C}$ in a $\mathrm{N}_{2}$ atmosphere. 


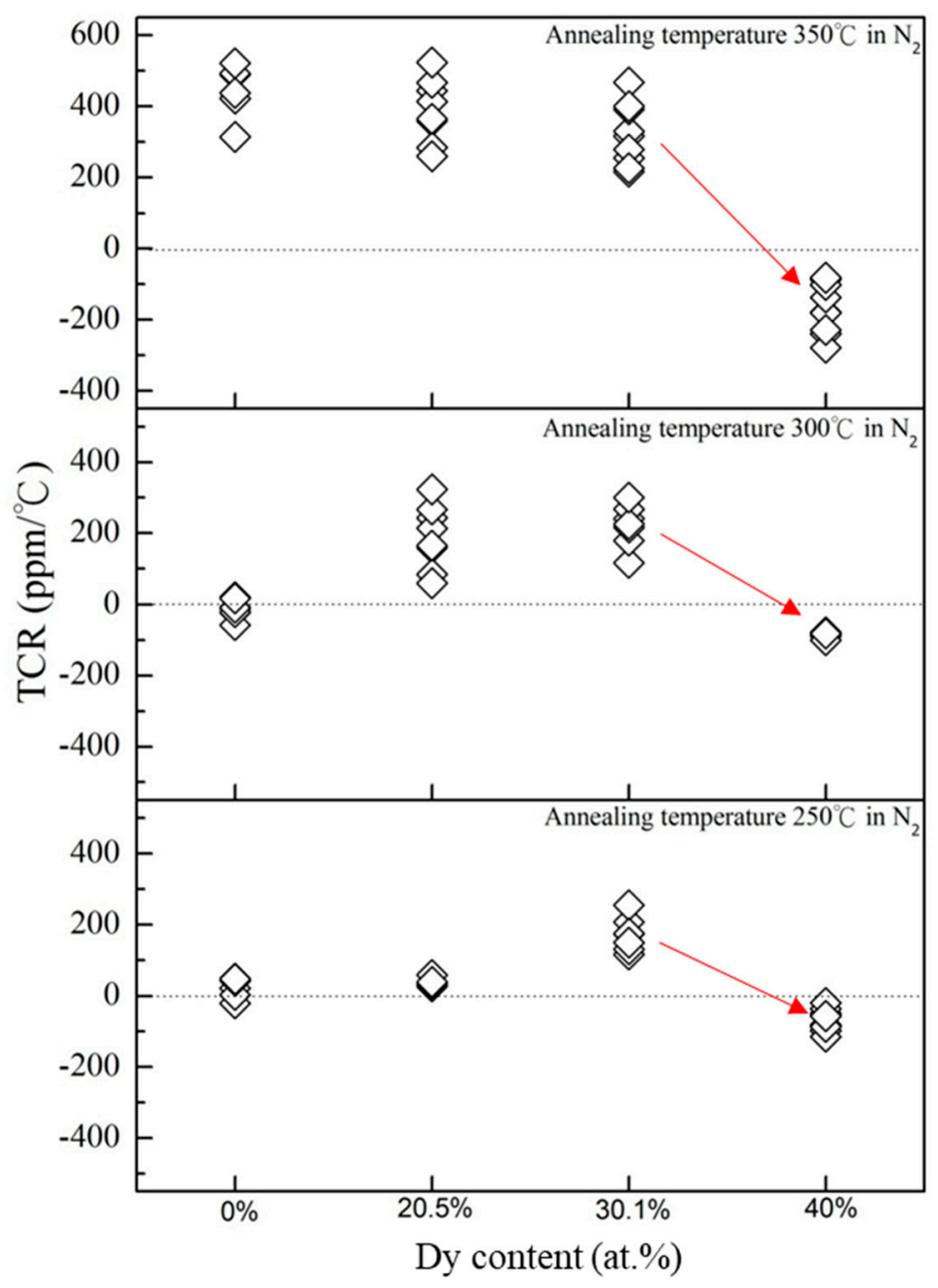

Figure 6. Temperature dependence of the temperature coefficient of resistance (TCR) of Cu-Mn films with various Dy contents annealed at different temperatures.

\section{Conclusions}

In this study, we prepared $\mathrm{Cu}-\mathrm{Mn}$-Dy thin films for the purpose of fabricating thin film resistors with high resistivity and low TCR. The effects of annealing temperature and Dy content on the electrical properties of the $\mathrm{Cu}-\mathrm{Mn}-\mathrm{Dy}$ thin film were investigated. Our conclusions are summarized as follows.

For the $\mathrm{Cu}-\mathrm{Mn}$ resistive thin films, $\mathrm{Cu}$ and $\mathrm{MnO}$ crystalline phases existed when the annealing temperature was $300^{\circ} \mathrm{C}$. When the annealing temperature was $\geq 350^{\circ} \mathrm{C}, \mathrm{Cu}, \mathrm{MnO}$ and $\mathrm{Cu}_{2} \mathrm{O}$ crystalline phases were presented in the $\mathrm{Cu}-\mathrm{Mn}$ films.

For the $\mathrm{Cu}-\mathrm{Mn}-\mathrm{Dy}$ resistive thin films, all $\mathrm{Cu}-\mathrm{Mn}-\mathrm{Dy}$ films annealed at $\leq 300{ }^{\circ} \mathrm{C}$ had an amorphous structure. This means that Dy addition in $\mathrm{Cu}-\mathrm{Mn}$ alloy films can suppress the $\mathrm{Cu}$ crystalline formation and $\mathrm{Mn}$ oxidation. However, there was still the $\mathrm{Cu}$ crystalline phase on the bottom part of the film and $\mathrm{Cu}_{2} \mathrm{O}$ phase on the film surface when the annealing temperature was $350{ }^{\circ} \mathrm{C}$. The $\mathrm{Cu}-\mathrm{Mn}$ films with 40 at. $\%$ Dy addition that were annealed at $300^{\circ} \mathrm{C}$ exhibited a resistivity of $\sim 2100 \mu \Omega \cdot \mathrm{cm}$ with the smallest temperature coefficient of resistance $\left(-85 \mathrm{ppm} /{ }^{\circ} \mathrm{C}\right)$.

Author Contributions: Data curation, H.-Y.L.; Formal analysis, C.-W.H.; Funding acquisition, D.-C.W.; Methodology, Y.-C.L.

Funding: The authors would like to acknowledge the financial support of this research from the Ministry of Science and Technology of Taiwan under contract No. 106-2221-E-020-009.

Conflicts of Interest: The authors declare no conflict of interest. 


\section{References}

1. Chuang, N.C.; Lin, J.T.; Chen, H.R. TCR control of Ni-Cr resistive film deposited by DC magnetron sputtering. Vacuum 2015, 119, 200-203. [CrossRef]

2. Matsuda, K.; Sato, K.; Doi, T.; Ogata, K.; Konishi, K. Super precision metal film resistors. National Tech. Rep. 1980, 26, 283-288.

3. Wang, X.Y.; Zhang, Z.S.; Bai, T. Investigation on powder metallurgy Cr-Si-Ta-Al alloy target for high-resistance thin film resistors with low temperature coefficient of resistance. Mater. Des. 2010, 31, 1302-1307. [CrossRef]

4. Kim, E.M.; Kim, S.C.; Lee, S. Electrical Properties of Cu/Mn Alloy Resistor with Low Resistance and Thermal Stability. J. Korean Inst. Electr. Electron. Mater. Eng. 2016, 29, 365-369.

5. Pearson, W.B. A Handbook of Lattice Parameters and Structures in Metals and Alloys; Pergamon Press: London, UK, 1958; Volume 1.

6. Iijima, J.; Fujii, Y.; Neishi, K.; Koikea, J. Resistivity reduction by external oxidation of Cu-Mn alloy films for semiconductor interconnect application. J. Vac. Sci. Technol. B 2009, 27, 1963-1968. [CrossRef]

7. Wu, C.Y.; Wu, C.T.; Lee, W.H.; Chang, S.C.; Wang, Y.L. A study on annealing mechanisms with different manganese contents in CuMn alloy. J. Alloys Comp. 2012, 542, 118-123. [CrossRef]

8. Misjak, F.; Nagy, K.H.; Lobotka, P.; Radnoczi, G. Electron scattering mechanisms in Cu-Mn films for interconnect applications. J. Appl. Phys. 2014, 116, 083507. [CrossRef]

9. Govindarajan, S.; Boscke, T.S.; Sivasubramani, P.; Kirsch, P.D.; Lee, B.H.; Tseng, H.H.; Jammy, R.; Schroder, U.; Ramanathan, S.; Gnade, B.E. Higher permittivity rare earth doped $\mathrm{HfO}_{2}$ for sub-45-nm metal-insulator-semiconductor devices. Appl. Phys. Lett. 2007, 91, 062906. [CrossRef]

10. Du, Q.; Huang, Z.; Wu, Z.; Meng, X.; Yin, G.; Gao, F.; Wang, L. Facile preparation and bifunctional imaging of Eu-doped GdPO4 nanorods with MRI and cellular luminescence. Dalton Trans. 2015, 44, 3934-3940. [CrossRef]

11. Gu, D.; Sun, Z.; Zhou, X.; Guo, R.; Wang, T.; Jiang, Y. Effect of yttrium-doping on the microstructures and semiconductor-metal phase transition characteristics of polycrystalline $\mathrm{VO}_{2}$ thin films. Appl. Surf. Sci. 2015, 359, 819-825. [CrossRef]

12. Asanuma, H.; Suzuki, T.; Kusunoki, T. An investigation of optimal interfacial film condition for Cu-Mn alloy based source/drain electrodes in hydrogenated amorphous silicon thin film transistors. AIP Adv. 2012, 2, 022147. [CrossRef]

13. Javed, A.; Durrani, H.G.; Zhu, C. The effect of vacuum annealing on the microstructure, mechanical and electrical properties of tantalum films. Int. J. Refract. Met. Hard Mater. 2016, 54, 154-158. [CrossRef]

14. Liu, L.; Gong, H.; Wang, Y.; Wang, J.; Wee, A.T.S.; Liu, R. Annealing effects of tantalum thin films sputtered on [001] silicon substrate. Mater. Sci. Eng. C 2001, 16, 85-89. [CrossRef]

15. Lee, S.-K.; Hsu, H.C.; Tuan, W.H. Oxidation Behavior of Copper at a Temperature below $300{ }^{\circ} \mathrm{C}$ and the Methodology for Passivation. Mater. Res. 2016, 19, 51-56. [CrossRef]

16. Xu, C.H.; Woo, C.H.; Shi, S.Q. Formation of $\mathrm{CuO}$ nanowires on Cu foil. Chem. Phys. Lett. 2004, 399, $62-66$. [CrossRef]

17. Zhou, G.; Yang, J.C. Temperature effect on the $\mathrm{Cu}_{2} \mathrm{O}$ oxide morphology created by oxidation of $\mathrm{Cu}(001)$ as investigated by in situ UHV TEM. Appl. Surf. Sci. 2003, 210, 165-170. [CrossRef]

18. Wang, Z.; Qin, C.; Liu, L.; Wang, L.; Ding, J.; Zhao, W. Synthesis of $\mathrm{Cu} \times \mathrm{O}(\mathrm{x}=1$,2)/Amorphous Compounds by Dealloying and Spontaneous Oxidation Method. Mater. Res. 2014, 17, 33-37. [CrossRef]

19. Otsuka, Y.; Koike, J.; Sako, H.; Ishibashi, K.; Kawasaki, N.; Chung, S.M.; Tanaka, I. Graded composition and valence states in self-forming barrier layers at $\mathrm{Cu}-\mathrm{Mn} / \mathrm{SiO}_{2}$ interface. Appl. Phys. Lett. 2010, 96, 012101. [CrossRef]

20. Lozano, J.G.; Lozano-Perez, S.; Bogan, J.; Wang, Y.C.; Brennan, B.; Nellist, P.D.; Hughes, G. Interdiffusion and barrier layer formation in thermally evaporated $\mathrm{Mn} / \mathrm{Cu}$ heterostructures on substrates. Appl. Phys. Lett. 2011, 98, 123112. [CrossRef]

21. Zhang, Y.; Zhou, Y.J.; Lin, J.P.; Chen, G.L.; Liaw, P.K. Solid-solution phase formation rules for multi-component alloys. Adv. Eng. Mater. 2008, 10, 534-538. [CrossRef]

22. Tsai, M.; Wang, C.; Tsai, C.; Shen, W.; Ye, J.; Wu, J.; We, G. Thermal stability and performance of NbSiTaTiZr high-entropy alloy barrier for copper metallization. J. Electrochem. Soc. 2011, 158, H1161. [CrossRef] 
23. Dong, X.; Wu, J. Study on the crystallization of amorphous $\mathrm{Cr}-\mathrm{Si}-\mathrm{Ni}$ thin films using in situ X-ray diffraction. J. Mater. Sci. Technol. 2001, 17, s43-s46.

24. Cheng, H.Y.; Chen, Y.C.; Li, P.J.; Yang, C.F.; Huang, H.H. Effect of Annealing Process on the Properties of $\mathrm{Ni}(55 \%) \mathrm{Cr}(40 \%) \mathrm{Si}(5 \%)$ Thin-Film Resistors. Materials 2015, 8, 6752-6760. [CrossRef] [PubMed]

25. Lee, B.J.; Lee, D.C. Electrical Properties of Sputtered Ni-Cr-Al-Cu Thin Film Resistors with Ni and Cr Contents. J. Kor. Phys. Soc. 2002, 40, 339-343.

26. Vinayak, S.; Vyas, H.P.; Vankar, V.D. Microstructure and electrical characteristics of Ni-Cr thin films. Thin Solid Films 2007, 515, 7109-7116. [CrossRef]

(C) 2019 by the authors. Licensee MDPI, Basel, Switzerland. This article is an open access article distributed under the terms and conditions of the Creative Commons Attribution (CC BY) license (http:// creativecommons.org/licenses/by/4.0/). 